\title{
Development of Arduino-based Data Acquisition System for Environmental Monitoring using Zigbee Communication Protocol
}

\author{
Busari Sherif A.*, Dunmoye Abibat F., Akingbade Kayode F. \\ Department of Electrical and Electronics Engineering, \\ School of Engineering and Engineering Technology, \\ Federal University of Technology, PMB 704 Akure, Ondo State, Nigeria \\ *Corresponding author, e-mail: sabusari@ futa.edu.ng
}

\begin{abstract}
Data Acquisition Systems (DAS) are used for a variety of applications such as environmental monitoring, indoor climate control, health management and medical diagnostics, traffic surveillance and emergency response, disaster management among others. This paper presents the design of a DAS for monitoring environmental temperature, pressure and relative humidity. The system employs Arduino Uno microcontroller for signal processing and Zigbee transceivers operating on the $2.4 \mathrm{GHz}$ license-free Industrial, Scientific and Medical (ISM) band as communication modules at both the transmitter and receiver ends. While the transmitter board houses the sensors, a GPS module and an LCD, the receiver system is interfaced with a PC which runs a developed MATLAB GUI for data display and analysis and it incorporates an SD card for data storage. The battery-powered system is a low cost, lowpower consumption system which serves as a mini-weather station with real-time data logging, wireless communication and tracking capabilities.
\end{abstract}

Keywords: Data Acquisition System, Sensor, Arduino Uno microcontroller, Zigbee Transceiver, 2.4 GHz ISM band

Copyright (C) 2016 APTIKOM - All rights reserved.

\section{Introduction}

Data acquisition is the process of taking a real-world signal (such as temperature, pressure, humidity etc) as input into the computer, after sensing and transduction, for processing, analysis and storage [1]. Data acquisition systems (DAS) interface between the real world of physical parameters, which are analogue, and the artificial world of digital computation and control. The purpose of any data acquisition system is to gather useful measurement data for characterization, monitoring or control [2]. These systems are used for a variety of system monitoring operations in agricultural, military, industrial, commercial and medical applications [3]. Depending on the intended application, the parameters monitored by acquisition systems are varied. Typical examples of such applications are presented in [4-6].

Advances in wireless communication, networking and in hardware technologies such as microcontrollers have revolutionized the development of Data Acquisition Systems such that applicationspecific systems can now be developed with enhanced capabilities for accurate and real-time gathering, logging, viewing and analysis of data, at low cost, low power and optimal performance [7]. A low power DAS for monitoring environmental temperature, pressure and humidity is herein presented. These three environmental parameters are affected by each other, and variation in one brings about variation in others [8], hence the choice of variables.

\section{System Development and Methods}

The developed system was realized in four stages as shown in the flow chart of Figure 1. This system consists of two subsystems, the transmitting and receiving units, as shown in Figure 2. At the transmitting end, the sensors monitor their respective parameters which are sent to the microcontroller for processing, together with data streams from the GPS module. The processed data are sent to both the LCD and the transmitter for display and onward transmission respectively. At the receiving end, daa 
received are processed by a microcontroller and sent to the SD card for storage and to the PC via USB interface for display and analysis by the GUI designed for the purpose.



Figure 1. System Development Flowchart


Figure 2. Schematic Diagram of the developed DAS

\subsection{System Hardware Design}

The major driver metrics in sensor network designs include range, power consumption, data rate, cost, processing speed and reliability [9-11]. This design therefore combines the excellent, diverse features of the Arduino Uno microcontroller in the areas of programming, cost, reliability, memory and processing speed and the appropriateness of the Zigbee communication protocol in the areas of power, range and data rate, among other wireless technologies.

The Zigbee protocol (IEEE 802.15.4), a Low-Rate Wireless Personal Area network (LR-WPAN), provides a standard for ultra-low complexity, ultra-low cost, low power consumption and low data rate wireless connectivity among inexpensive devices for sensing and controlling applications [12]. Based on the sensing, power and communication demands of the system, the design specifications presented in Table 1 were set to meet the required application. Based on the design specifications, the various components of the system, shown in Figure 3, were selected based on their operating parameters and features. 
Table 1. System design specifications

\begin{tabular}{cc}
\hline Parameter & Specification \\
\hline Power & $<1 \mathrm{~W}$ \\
Current Drain & $<0.5 \mathrm{~A}$ \\
Frequency & $2.4 \mathrm{GHz}$ \\
Range & $<1 \mathrm{~km}$ \\
Data rate & $250 \mathrm{~kb} / \mathrm{s}(\max )$ \\
\hline
\end{tabular}
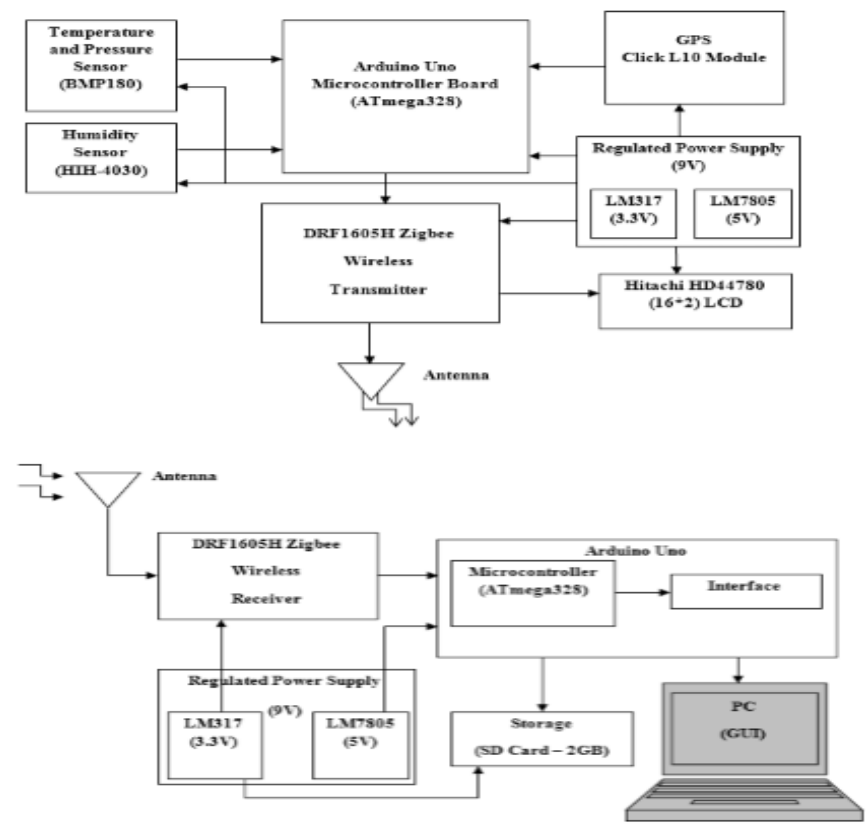

Figure 3. Components of the System

The design of the subsystems was done using ISIS Proteus Design Suite. The final circuitry of the systems, after simulations and optimization, are presented in Figures 4 and 5.

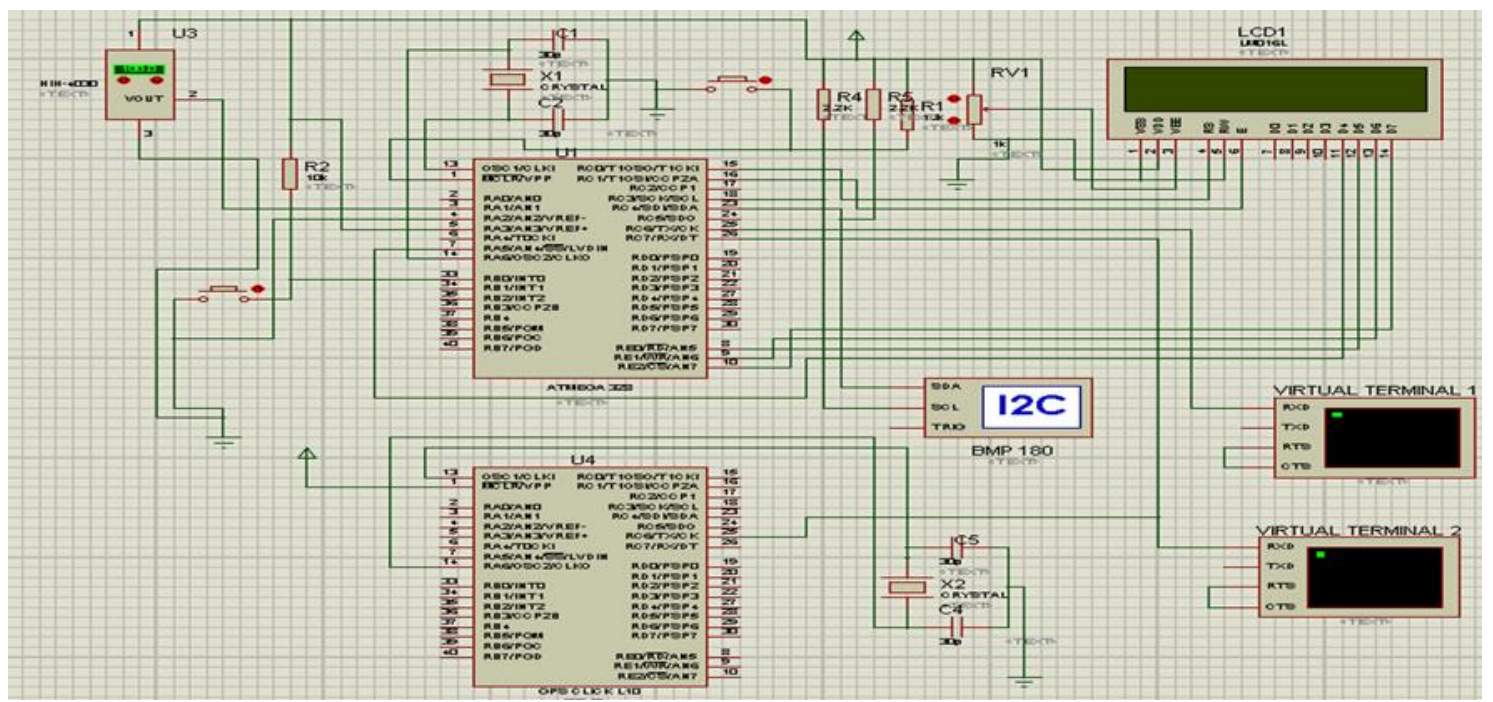

Figure 4. Circuit Diagram for the Transmitting Subsystem 


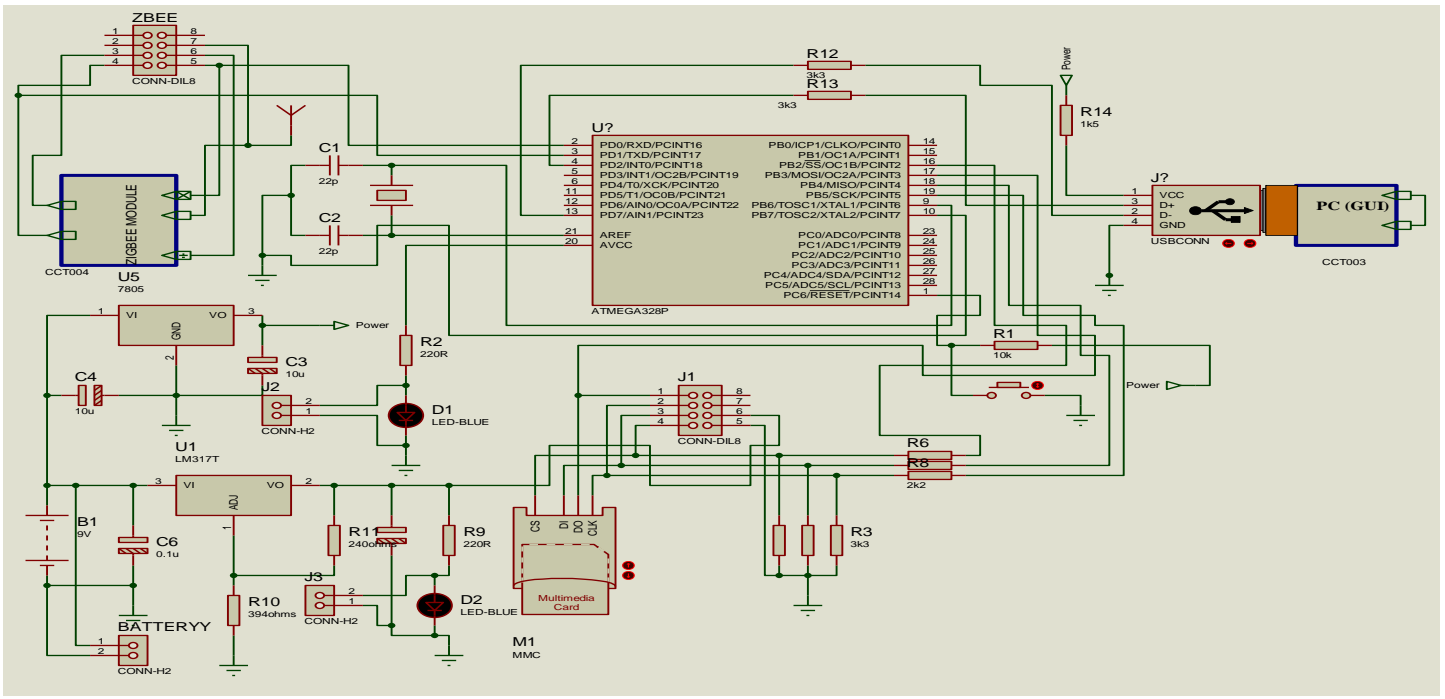

Figure 5. Circuit Diagram for the Receiving Subsystem

\subsection{System Software Design}

The software applications of the system development are in three phases: Zigbee configuration, microcontroller coding and GUI design.

The DRF1605H transceivers were configured using the Zigbee Module Configure V5.1 shown in Figure 6, to transmit and receive on channel 14 within the license-free Industrial, Scientific and Medical (ISM) band (2400-2483.5 MHz band). The centre frequency of the transceivers is calculated using (1).

$$
f_{c}=2405+5(k-11) M H z ; \quad \mathrm{k}=11,12, \ldots, 26
$$

where $\mathrm{k}$ is the channel number. For channel $14, \mathrm{k}=14, f_{c}=2420 \mathrm{MHz}$.

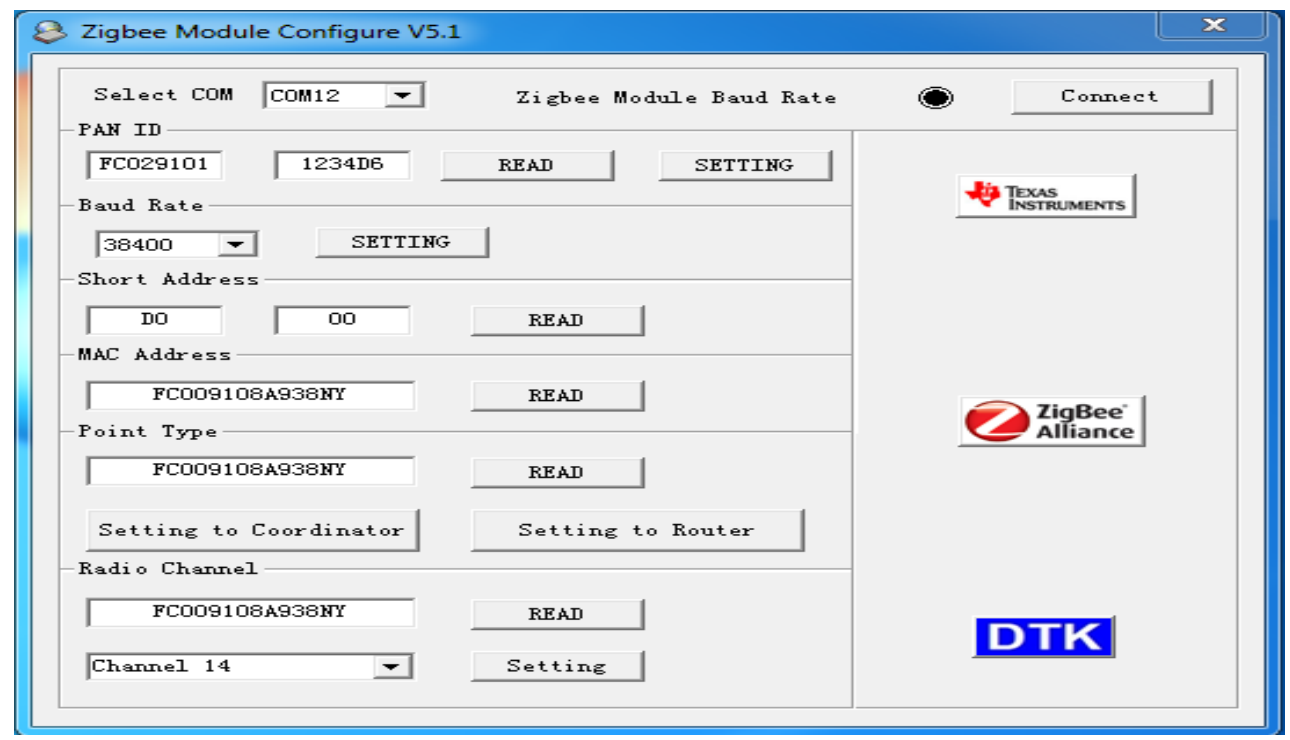

Figure 6. DRF1605H transceiver configuration software 
For microcontroller programming, the code/sketch for the Arduino microcontroller (ATmega328) was written in the Arduino Integrated Development Environment (IDE) shown in Figure 7. The ATmega328 on the Arduino Uno is preburned with a bootloader that allows new codes to be uploaded to it without the use of an external hardware programmer. It communicates using the STK500 protocol or through the ICSP (In-Circuit Serial Programming) header.

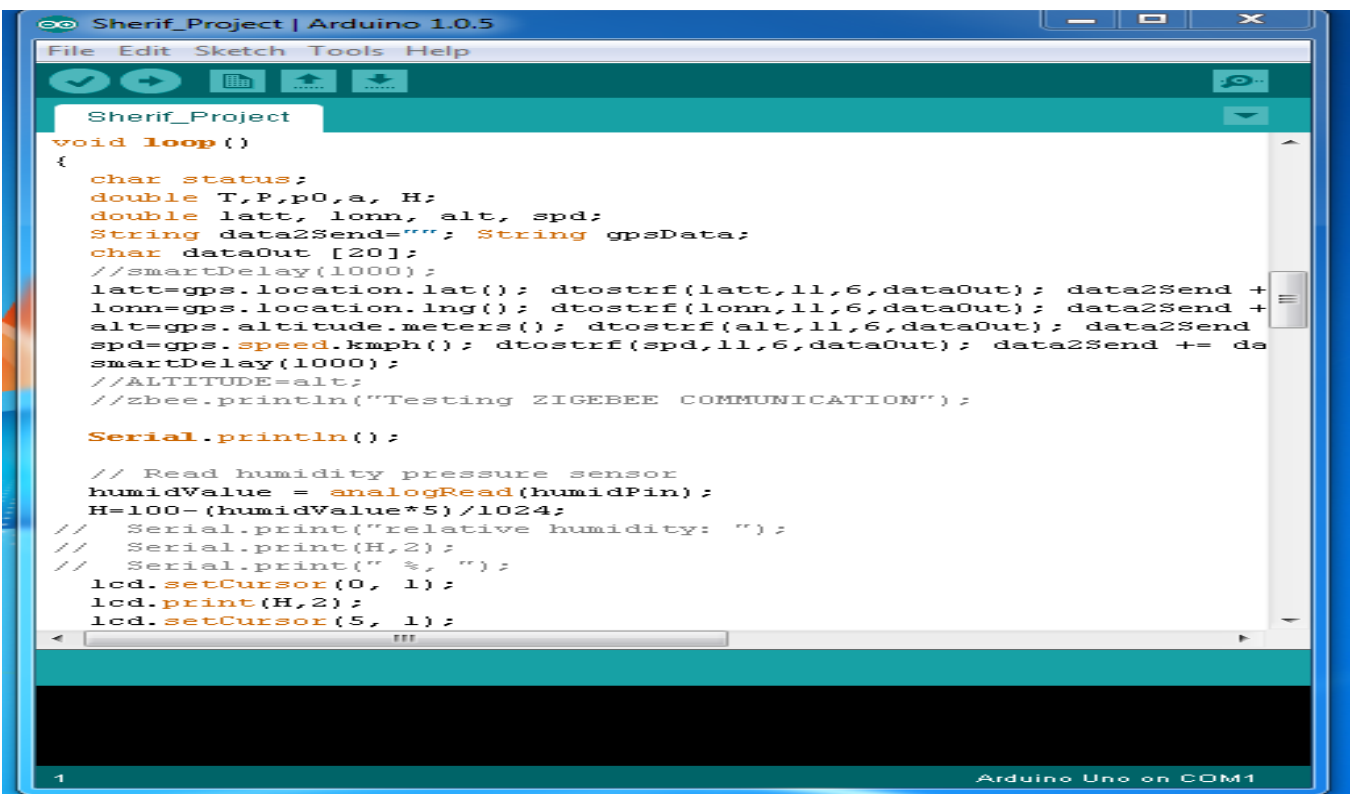

Figure 7. Arduino Integrated Development Environment

A GUI platform was developed using MATLAB programming software to interact with the hardware, for data display, plotting and analysis. The developed interface is shown in Figure 8.

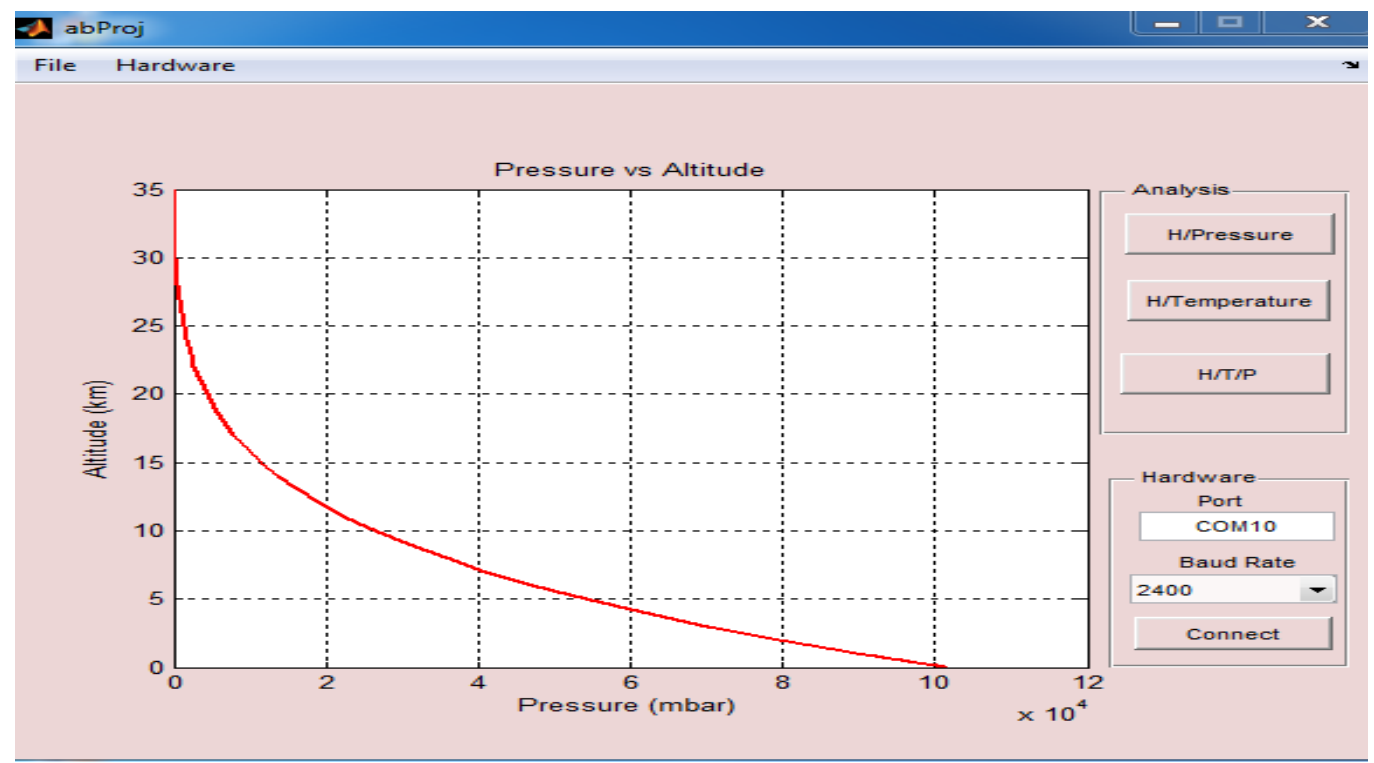

Figure 8. Developed GUI using MATLAB showing altitude $(\mathrm{km})$ against pressure (mbar) 


\section{Results and Discussion}

The power consumption for the two subsystems are presented in Tables 2 and 3, which show that the current drain and power consumption of the individual subsystem are less than $0.5 \mathrm{~A}$ and $1 \mathrm{~W}$ respectively as set in the design specifications. More so, the transceivers are configured to periodically transmit and receive at intervals of $10 \mathrm{~s}$. This therefore means that the indicated values are the maximum possible values when the subsystems are in transmit/receive mode, as against when in sleep/idle modes.

Table 2. Power Analysis of the Transmitting subsystem

\begin{tabular}{cllccc}
\hline S/No. & \multicolumn{1}{c}{ Component } & Product Name/Vendor & $\begin{array}{c}\text { Operatin } \\
\text { g Voltage } \\
(\mathrm{V})\end{array}$ & $\begin{array}{c}\text { Max. Current } \\
\text { Drain } \\
(\mathrm{mA})\end{array}$ & $\begin{array}{c}\text { Max. Power } \\
\text { Consumption } \\
(\mathrm{mW})\end{array}$ \\
\hline 1 & & Temperature and Pressure Sensor & BMP180 (Bosch) & 3.3 & 0.005 \\
2 & Relative Humidity Sensor & HIH-4030 (Honeywell) & 5.0 & 0.500 & 0.0165 \\
3 & Arduino Microcontroller & ATMEGA328 (Atmel) & 5.0 & 50.000 & 2.5000 \\
4 & GPS & Click L10 (MikroElectronika) & 3.3 & 38.000 & 125.4000 \\
5 & Transmitter & DRF1605H (DTK Electronics) & 3.3 & 120.000 & 396.0000 \\
6 & LCD & HD44780 (16*2) (Hitachi) & 5.0 & 4.000 & 20.0000 \\
TOTAL & & & & 213 & 794 \\
\hline
\end{tabular}

Table 3. Power Analysis of the Receiving subsystem

\begin{tabular}{cllccc}
\hline S/No. & \multicolumn{1}{c}{ Component } & \multicolumn{1}{c}{ Product Name/Vendor } & $\begin{array}{c}\text { Operating } \\
\text { Voltage (V) }\end{array}$ & $\begin{array}{c}\text { Max. Current } \\
\text { Drain (mA) }\end{array}$ & $\begin{array}{c}\text { Max. Power } \\
\text { Consumption (mW) }\end{array}$ \\
\hline 1 & Arduino Microcontroller & ATMEGA328 (Atmel) & 5 & 50 & 250.0 \\
2 & Receiver & DRF1605H (DTK Electronics) & 3.3 & 45 & 148.5 \\
TOTAL & & & 95 & 398.5 \\
\hline
\end{tabular}

Figure 9 shows a sample of the transmitted, received and logged data at a particular instant of time, which had been programmed to communicate at intervals of $10 \mathrm{~s}$. The transmitted, received and logged data are the same which validates the reliability of the data communication of the system.

\begin{tabular}{|c|c|c|c|c|c|c|c|c|c|}
\hline & $\begin{array}{l}\text { Lat. } \\
\left({ }^{\circ}\right)\end{array}$ & $\begin{array}{c}\text { Long. } \\
\left({ }^{\circ}\right)\end{array}$ & $\begin{array}{l}\text { Alt. } \\
\text { (m) }\end{array}$ & $\begin{array}{l}\text { Wind Vel. } \\
(\mathrm{m} / \mathrm{s})\end{array}$ & $\begin{array}{l}\text { Date } \\
\mathrm{m} / \mathrm{d} / \mathrm{y}\end{array}$ & $\begin{array}{l}\text { Time } \\
\text { h:m:s }\end{array}$ & $\begin{array}{l}\mathrm{RH} \\
(\%)\end{array}$ & $\begin{array}{c}\text { Temp. } \\
\left({ }^{\circ} \mathrm{C}\right)\end{array}$ & $\begin{array}{l}\text { Pres. } \\
\text { (mbar) }\end{array}$ \\
\hline (i) & $\begin{array}{c}7.3027 \\
90\end{array}$ & 5.135531 & 422.799990 & 0.037040 & $\begin{array}{c}10 / 08 / 201 \\
4\end{array}$ & $13: 47: 11$ & 98.00 & 28.84 & 968.85 \\
\hline (ii) & $\begin{array}{c}7.3027 \\
90\end{array}$ & 5.135531 & 422.799990 & 0.037040 & $\begin{array}{c}10 / 08 / 201 \\
4\end{array}$ & $13: 47: 11$ & 98.00 & 28.84 & 968.85 \\
\hline (iii) & $\begin{array}{c}7.3027 \\
90 \\
968.85 \\
\end{array}$ & 5.135531 & 422.799990 & 0.037040 & $\begin{array}{c}10 / 08 / 201 \\
4\end{array}$ & $13: 47: 11$ & 98.00 & 28.84 & 28.84 \\
\hline
\end{tabular}

Figure 9. Transmitted Data (i), Received Data (ii), and Logged Data on the Micro SD Card (iii) at a particular instant of time

Also, test results of data samples at three different altitudes for three days taken at the Federal University of Technology, Akure, Nigeria (lat. $7.303^{\circ} \mathrm{N}$, long. $5.135^{\circ} \mathrm{E}$ ) as presented in Tables 4 and 5 show insignificant deviations thereby confirming the reliability and consistency of the system. 
Table 4. Comparison of data samples at same altitude for same days

\begin{tabular}{|c|c|c|c|c|c|c|c|c|}
\hline $\begin{array}{l}\text { Date } \\
\mathrm{m} / \mathrm{d} / \mathrm{yr}\end{array}$ & $\begin{array}{l}\text { Time } \\
\text { h:m:s }\end{array}$ & $\begin{array}{l}\text { Lat. } \\
\left({ }^{\circ}\right)\end{array}$ & $\begin{array}{l}\text { Long. } \\
\left({ }^{\circ}\right)\end{array}$ & $\begin{array}{l}\text { Wind Velocity } \\
(\mathrm{m} / \mathrm{s})\end{array}$ & $\begin{array}{l}\text { Alt. } \\
(\mathrm{m})\end{array}$ & $\begin{array}{l}\mathrm{RH} \\
(\%)\end{array}$ & $\begin{array}{l}\text { Temp. } \\
\left({ }^{\circ} \mathrm{C}\right)\end{array}$ & $\begin{array}{l}\text { Pres. } \\
\text { (mbar) }\end{array}$ \\
\hline $10 / 7 / 2014$ & $14: 36: 38$ & 7.303035 & 5.135527 & 1.35196 & 441.6 & 98 & 28.24 & 968.97 \\
\hline $10 / 7 / 2014$ & $14: 36: 49$ & 7.303003 & 5.135512 & 0.87044 & 441.6 & 98 & 28.28 & 968.88 \\
\hline $10 / 7 / 2014$ & $14: 37: 00$ & 7.302995 & 5.135547 & 1.59272 & 441.6 & 98 & 28.41 & 968.55 \\
\hline $10 / 8 / 2014$ & $13: 31: 33$ & 7.302600 & 5.135467 & 0.25928 & 435.2 & 98 & 28.55 & 969.05 \\
\hline $10 / 8 / 2014$ & $13: 35: 53$ & 7.302578 & 5.135433 & 0.01852 & 435.2 & 98 & 28.51 & 968.89 \\
\hline $10 / 8 / 2014$ & $13: 36: 04$ & 7.302578 & 5.135433 & 0.07408 & 435.2 & 98 & 28.53 & 968.98 \\
\hline $10 / 9 / 2014$ & $10: 27: 53$ & 7.302698 & 5.135750 & 0.22224 & 430.7 & 97 & 26.80 & 971.20 \\
\hline $10 / 9 / 2014$ & $10: 28: 05$ & 7.302691 & 5.135745 & 0.33336 & 430.7 & 97 & 26.78 & 971.20 \\
\hline $10 / 9 / 2014$ & $10: 28: 16$ & 7.302685 & 5.135746 & 0.31484 & 430.7 & 97 & 26.75 & 971.23 \\
\hline
\end{tabular}

Table 5. Comparison of data samples at same altitude for different days

\begin{tabular}{|c|c|c|c|c|c|c|c|c|}
\hline $\begin{array}{l}\text { Date } \\
\mathrm{m} / \mathrm{d} / \mathrm{yr}\end{array}$ & $\begin{array}{l}\text { Time } \\
\mathrm{h}: \mathrm{m}: \mathrm{s}\end{array}$ & $\begin{array}{l}\text { Lat. } \\
\left({ }^{\circ}\right)\end{array}$ & $\begin{array}{l}\text { Long. } \\
\left({ }^{\circ}\right)\end{array}$ & $\begin{array}{l}\text { Wind Velocity } \\
(\mathrm{m} / \mathrm{s})\end{array}$ & $\begin{array}{l}\text { Alt. } \\
(\mathrm{m})\end{array}$ & $\begin{array}{l}\mathrm{RH} \\
(\%)\end{array}$ & $\begin{array}{l}\text { Temp. } \\
\left({ }^{\circ} \mathrm{C}\right)\end{array}$ & $\begin{array}{l}\text { Pres. } \\
(\mathrm{mbar})\end{array}$ \\
\hline $10 / 7 / 2014$ & $14: 29: 29$ & 7.303135 & 5.135503 & 4.57444 & 408.1 & 97 & 28.73 & 969.37 \\
\hline $10 / 8 / 2014$ & $13: 28: 32$ & 7.302840 & 5.135667 & 0.40744 & 408.0 & 98 & 28.25 & 969.18 \\
\hline $10 / 9 / 2014$ & $10: 41: 25$ & 7.302720 & 5.135640 & 0.11112 & 409.0 & 97 & 27.37 & 970.00 \\
\hline $10 / 7 / 2014$ & $14: 44: 03$ & 7.302832 & 5.135373 & 5.09300 & 427.0 & 98 & 29.64 & 968.56 \\
\hline $10 / 8 / 2014$ & $13: 38: 53$ & 7.302698 & 5.135472 & 0.03704 & 427.0 & 98 & 28.72 & 968.95 \\
\hline $10 / 9 / 2014$ & $12: 00: 41$ & 7.303130 & 5.135833 & 1.27788 & 427.2 & 97 & 28.05 & 969.94 \\
\hline $10 / 7 / 2014$ & $14: 44: 43$ & 7.302845 & 5.135344 & 1.42604 & 428.7 & 98 & 29.28 & 968.63 \\
\hline $10 / 8 / 2014$ & $13: 30: 13$ & 7.302633 & 5.135470 & 0.83340 & 429.1 & 98 & 28.49 & 969.11 \\
\hline $10 / 9 / 2014$ & $10: 29: 24$ & 7.302580 & 5.135752 & 0.38892 & 429.0 & 97 & 27.00 & 971.21 \\
\hline
\end{tabular}

The experimental set-up at the Idanre Hills, Idanre, Ondo State, Nigeria (lat. $7.302832^{\circ} \mathrm{N}$, long. $5.135373^{\circ} \mathrm{E}$ ) on $22^{\text {nd }}$ October, 2014 between 9:26:33 and 10:59:11 GMT for a differential altitude of $137.5 \mathrm{~m}$ (i.e. 327.0 to $464.5 \mathrm{~m}$ above sea level for the ground and maximum mountain point reached respectively) was carried out in which 855 data streams were sent from the transmitter node to the receiver node and abridged data at intervals of $10 \mathrm{~m}$ altitude is presented in Table 6 and the graph of temperature, pressure and relative humidity against altitude (above sea level) shown in Figures 10 to 12 revealed that temperature shows a decreasing trend from $28.04^{\circ} \mathrm{C}$ at $327 \mathrm{~m}$ to $24.97^{\circ} \mathrm{C}$ at $447.2 \mathrm{~m}$ (though slightly shooting up to $29.28^{\circ} \mathrm{C}$ and $30.13^{\circ} \mathrm{C}$ at 457.8 and $464.5 \mathrm{~m}$ respectively), pressure shows a decreasing trend from 979.26 mbar to 963.59 mbar at $327.0 \mathrm{~m}$ and $464.5 \mathrm{~m}$ respectively while relative humidity maintained a value of $97 \%$ between 327 and $447.2 \mathrm{~m}$ (above sea level) and $98 \%$ between 447.2 and $464.5 \mathrm{~m}$, respectively.

Table 6. Field test results

\begin{tabular}{cccc}
\hline Altitude $(\mathrm{m})$ & Relative Humidity $(\%)$ & Temperature $\left({ }^{\circ} \mathrm{C}\right)$ & Pressure (mbar) \\
\hline 327.0 & 97 & 28.04 & 979.26 \\
337.0 & 97 & 27.91 & 978.06 \\
347.2 & 97 & 28.58 & 977.49 \\
357.8 & 97 & 27.36 & 975.60 \\
367.8 & 97 & 27.51 & 976.76 \\
376.5 & 97 & 27.05 & 976.41 \\
387.1 & 97 & 27.11 & 973.68 \\
395.3 & 97 & 27.61 & 972.53 \\
407.1 & 97 & 27.36 & 971.34 \\
417.0 & 97 & 27.03 & 974.50 \\
426.9 & 97 & 26.54 & 967.80 \\
437.8 & 97 & 25.41 & 968.47 \\
447.2 & 97 & 24.97 & 967.07 \\
457.8 & 98 & 29.28 & 964.86 \\
464.5 & 98 & 30.13 & 963.59 \\
\hline
\end{tabular}




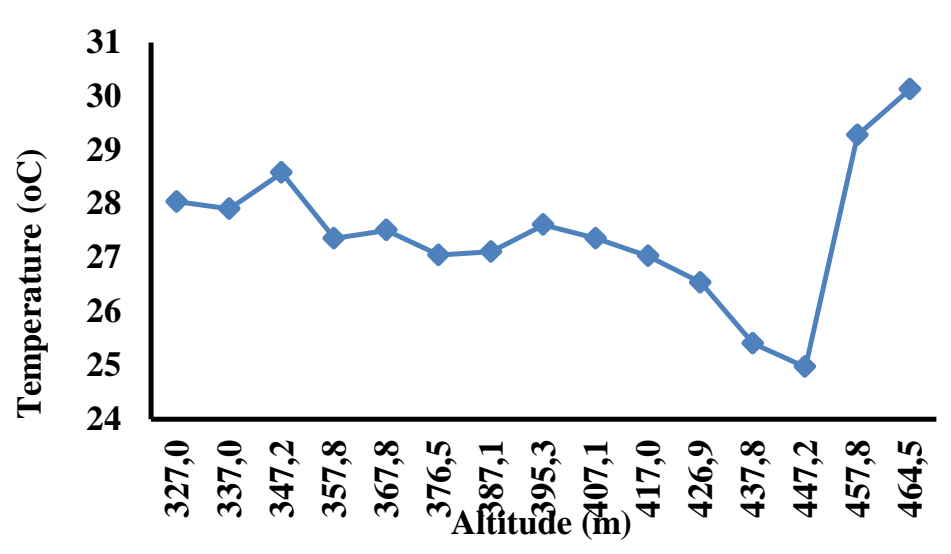

Figure 10. Plot of Temperature $\left({ }^{\circ} \mathrm{C}\right)$ against Altitude (m)

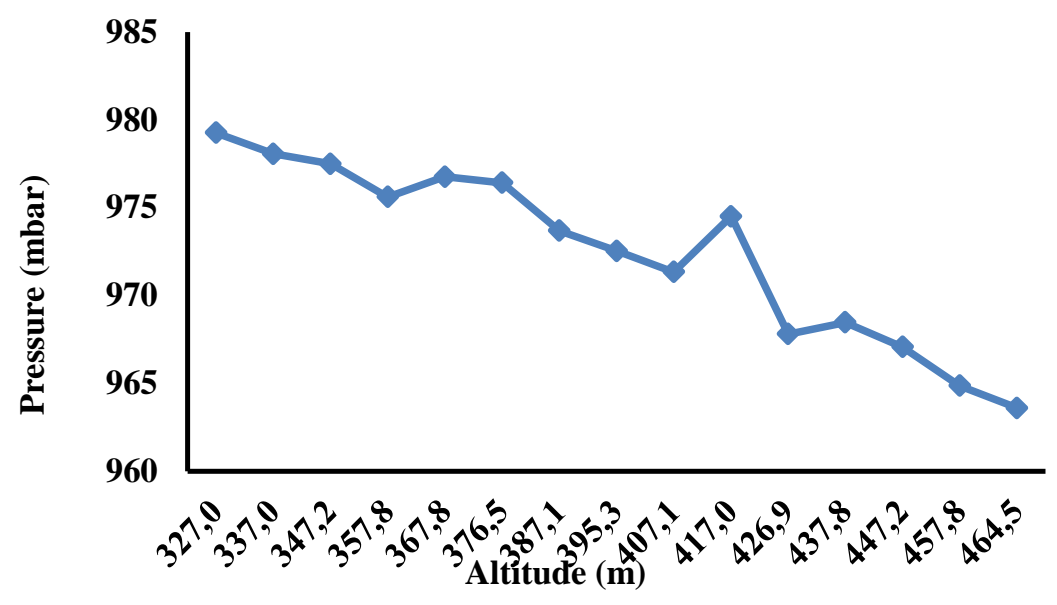

Figure 11. Plot of Pressure (mbar) against Altitude (m)

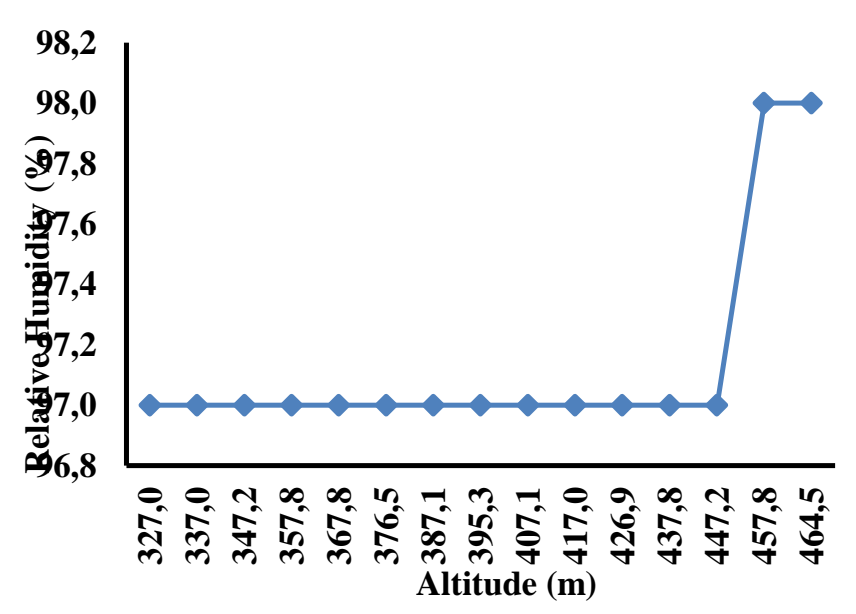

Figure 12. Plot of Relative Humidity (\%) against Altitude (m) 


\section{Conclusion}

A mini-weather station for atmospheric data acquisition with real-time sensing and data logging, wireless communication (using Zigbee protocol) and tracking capabilities was developed. This would be useful for diverse applications in environmental monitoring at home and on the fields.

With the developed system, real-time atmospheric profiling of Idanre, Ondo State, Nigeria, as a test study, has been carried out for a differential altitude of $137.5 \mathrm{~m}$ (i.e. $327.0 \mathrm{~m}$ to $464.5 \mathrm{~m}$ above sea level). The results show that temperature and pressure decreased with altitude while the relative humidity values maintained fairly-constant values of $97-98 \%$. These trends are consistent with models developed by [13]. The developed system is cost-effective and reliable and can be adapted for environmental monitoring, even in inaccessible places.

\section{References}

[1]. Sanjeev K. and Sayed M., "PC-Based Data Acquisition System", B.Eng Thesis, National Institute of Technology, Rourkela, India, 2008

[2]. Heintz D., "Essential Components of Data Acquisition Systems Application Note 1386", Agilent Technologies, USA, Available online at http://cp.literature.agilent.com/litweb/pdf/5988-5386EN.pdf_2002.

[3]. Saima M. and Ulya S., "Arising Issues in Wireless Sensor Networks: Current Proposals and Future Developments", IOSR Journal of Computer Engineering (IOSR-JCE), Vol. 8, Issue 6, pp 56-73, 2013.

[4]. Noor H. A., Suzi S. S., Kama A. O., Norfishah W., Norzatina M. and Ahmad T. H., "Supervisory Data Acquisition of Temperature and Humidity in oil palm Tissue Culture laboratory", International Conference on Computational Intelligence, Modelling and Simulation, IEEE, USA, pp 470-475, 2010

[5]. Haefke, M., Mukhopadhyay S. C. and Ewald H., "A Zigbee Based Smart Sensing Platform for Monitoring Environmental Parameters", Instrumentation and Measurement Technology Conference (I2MTC), IEEE 2011

[6]. Guha, S. K., Nabhiraj, P. Y., Bhaumik T. K. and Mallik C., "Design and Implementation of an IEEE 802.15.4 / Zigbee Based Star Network for Data Acquisition and Monitoring”, India Software and Hardware Technology, pp 160-162, Kolkata, India, 2012

[7]. Deepika D., "Designing a Microcontroller Based Temperature Data Logger", Master of Engineering Thesis, Department of Electrical and Instrumentation Engineering, Thapar Institute of Engineering and Technology, Deemed University, Patiala, India, 2006

[8]. Valsson S. and Bharat A., "Impact of Air Temperature on Relative Humidity - A study", Architecture - Time Space and People, Council of Architecture, New Delhi, India, 2011

[9]. Sokwoo Rhee and Sheng Liu, "Wireless Sensor Networking Source Book: A Guide to the Fundamentals of Wireless Sensor Networks", Millenial Net Inc., USA, 2005

[10].Mokhtar Aboelaze and Fadi Aloul, "Current and Future Trends in Sensor Networks: A Survey", IEEE, USA, 2005

[11].Martin Evans, Joshua Noble and Jordan Hochenbaum, “Arduino in Action”, Manning Publications Co., New York, USA, 2013

[12].IEEE, “IEEE Standards 802.15.4-2003, Standard for Information Technology - LAN and MAN", IEEE Computer Society, New Jersey, USA, 2003

[13].Nayak A., Sreejith A. G., Safonova M. and Murthy J.,"High-altitude ballooning programme at the Indian Institute of Astrophysics", Current Science, Vol. 104, No. 6, India, 2013

\section{Biographies of Authors}

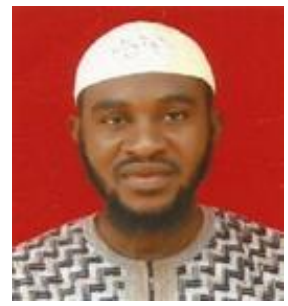

Busari, Sherif Adeshina is currently an Assistant Lecturer at the Department of Electrical and Electronics Engineering, Federal University of Technology Akure (FUTA), Nigeria. $\mathrm{He}$ obtained his B.Eng in Electrical and Electronics Engineering (2011) and M.Eng in Communication Engineering (2015) both from FUTA, Nigeria. His research interests include Wireless Sensor Networks, Wireless and Satellite Communication.

E-mail: sabusari@futa.edu.ng 


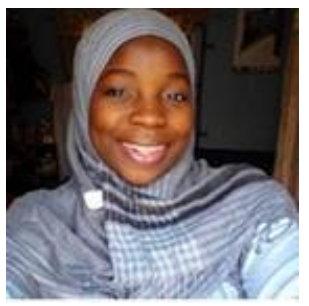

Dunmoye, Abibat Feyisayo obtained her B.Eng in Electrical and Computer Engineering from the Federal University of Technology Minna, Nigeria in 2008 and M.Eng in Electrical and Electronics Engineering (Communication option) in 2015 from the Federal University of Technology Akure, Nigeria. She is a CISCO certified network professional. Her research interests include Computer networking, Wireless Sensor Networks, Wireless Communication. E-mail: dunmoyefeyisayo@yahoo.co.uk

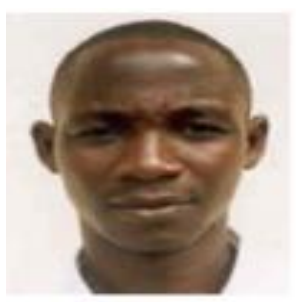

Akingbade, Kayode Francis is a Senior Lecturer in the Department of Electrical and Electronics Engineering, Federal University of Technology, Akure, Nigeria. He holds a $\mathrm{PhD}$ degree in Electrical Engineering (Communication) received from the Federal University of Technology, Akure, Nigeria in 2011. He has published over 20 refereed international journal and conference papers. His research interests include satellite communication, control systems and biomedical engineering. E-mail: kfakingbade@futa.edu.ng 